\title{
Subacute toxicopathological studies of methotrexate in Wistar rats
}

\author{
N. N. Patel, D. J. Ghodasara, Sunanda Pandey, Priya D. Ghodasara, J. H. Khorajiya, B. P. Joshi and C. J. Dave
}

Department of Veterinary Pathology,

College of Veterinary Science and Animal Husbandry, Anand Agricultural University, Anand, Gujarat - 388001, India

Corresponding author: D. J. Ghodasara, email: dinghodasara@gmail.com

NNP: nupur1989@gmail.com, SP: drsunandapandey@gmail.com,PDG:priyaghodasara@yahoo.com,

JHK: jainudeen_1990@rediffmail.com, BPJ: b4bpjoshi@gmail.com, CJD: c4cjdave@gmail.com

Received: 11-04-2014, Revised: 07-06-2014, Accepted: 11-06-2014, Published online: 16-07-2014

doi: $10.14202 /$ vetworld.2014.489-495

How to cite this article: Patel NN, Ghodasara DJ, Pandey S, Ghodasara PD, Khorajiya JH, Joshi BP and Dave CJ (2014) Subacute toxicopathological studies of methotrexate in Wistar rats, Veterinary World 7(7): 489-495.

\begin{abstract}
Aim: A toxico-pathological study was undertaken to assess the effects of Methotrexate administration in Wistar rats by performing the hematology, serum biochemical analysis and associated histopathological changes in visceral organs.

Materials and Methods: Rats in 4 treatment groups with 6 male and 6 female rats each were administered methotrexate (Group II to IV) at the dose rate of $0.062,0.125$ and $0.250 \mathrm{mg} / \mathrm{kg}$ body weight respectively and distilled water (Group I) as vehicle control for 28 days. Hematological parameters viz., total erythrocyte count, haemoglobin, packed cell volume, MCV, $\mathrm{MCH}$ and $\mathrm{MCHC}$, total leukocyte count and differential leukocyte count and serum biochemical parameters viz., aspartate aminotransferase, alanine aminotransferase, alkaline phosphatase, serum creatinine, blood urea nitrogen, total protein, albumin, globulin (Calculated) were estimated after 28 days. Necropsy examination was performed in all sacrificed animals and gross lesions were recorded. Tissue samples (lung, liver, kidney, intestine, testes and heart) were collected in $10 \%$ formalin solution for histo-pathological examination.
\end{abstract}

Results: The dose dependent reduction in body weight, feed consumption, RBCs count, packed cell volume, haemoglobin, total leucocyte count, neutrophil count, total protein and albumin was observed in animals of group II, III and IV along with significant increase in lymphocyte count, AST, ALT, AKP, creatinine and BUN in animals of methotrexate treated group IV followed by group III. No significant change in monocyte, eosinophil and basophil counts were observed in any treatment groups. All the rats exposed to methotrexate at three different dose levels revealed dose dependent pathological changes characterized by degeneration, necrosis, congestion, haemorrhage and vascular changes. The main target organs affected were liver, kidney, lungs and testes.

Conclusion: It can be concluded from this study that sub-acute exposure to methotrexate produced no appreciable changes at recommended $0.062 \mathrm{mg} / \mathrm{kg}$ body weight dose level. The findings observed at $0.250 \mathrm{mg} / \mathrm{kg}$ body weight methotrexate dose level are of public health significance and regulatory importance due to its hepatotoxic and nephrotoxic character.

Keywords: biochemical parameters, histopathology, methotrexate, Wistar rats.

\section{Introduction}

Methotrexate (MTX), a folic acid antagonist, currently used as a disease modifying anti-rheumatic drug (DMARD) along with non-steroidal anti-inflammatory drugs (NSAIDs) to provide the best possible relief to rheumatoid arthritis patients in low doses $(2.5$ $\mathrm{mg}-15 \mathrm{mg} /$ week) [1]. Rheumatoid arthritis is a chronic, systemic, autoimmune, inflammatory disorder of humans and animals like dog and horse which primarily affects joints resulting in non-suppurative proliferative synovitis [2]. Methotrexate is also used alone or in combination with other anticancer agents in the treatment of breast cancer, epidermoid cancers of the head and neck and lung cancer [3].

With the widespread use of methotrexate, a welldefined toxicity profile has emerged [4]. Methotrexate exerts its primary toxic effects against the rapidly replicating cells of the bone marrow and gastrointes-

Copyright: The authors. This article is an open access article licensed under the terms of the Creative Commons Attribution License (http://creativecommons.org/licenses/by/2.0) which permits unrestricted use, distribution and reproduction in any medium, provided the work is properly cited. tinal epithelium producing leucopoenia and thrombocytopenia. Long term administration of the same causes anaemia. Methotrexate also causes kidney damage, which is a frequent complication of high-dose therapy. Both low and high-dose therapy can cause hepatotoxicity. High-dose therapy results in elevated liver enzymes and low dose therapy produces a different type of hepatotoxicity which includes cirrhosis. Methotrexate at very low dosage affects the liver and causes changes in histology of liver in rat [5]. Other frequently reported adverse toxic effects are malaise, nausea, vomition, diarrhoea, headache, mild alopecia and fever [6].

Toxic side effects of methotrexate have been demonstrated in various animals including rat, mice, rabbit and dog. Methotrexate seems to be hepatotoxic, nephrotoxic and toxic to respiratory and reproductive system at very low doses for continuous therapy. The present study was conducted to examine the subacute toxicopathological effects of methotrexate in Wistar rats.

\section{Materials and Methods}

Ethical approval: Institutional Animal Ethics Committee 
Table-1a: Mean hematological values in different experimental groups.

\begin{tabular}{|c|c|c|c|c|c|c|c|c|c|c|c|c|c|c|c|c|}
\hline \multirow[t]{3}{*}{ Group } & \multirow[t]{3}{*}{ Dose (mg/kg) } & \multirow[t]{3}{*}{ Sex } & \multicolumn{2}{|c|}{$\operatorname{RBC}\left(\times 10^{6} / \mu \mathrm{L}\right)$} & \multirow{2}{*}{\multicolumn{2}{|c|}{ WBCs $\left(X 10^{3} / \mu L\right)$}} & \multicolumn{10}{|c|}{ Differential WBCs } \\
\hline & & & \multirow[b]{2}{*}{ Mean } & \multirow[b]{2}{*}{ SE } & & & \multicolumn{2}{|c|}{$N(\%)$} & \multicolumn{2}{|c|}{$L(\%)$} & \multicolumn{2}{|c|}{ M (\%) } & \multicolumn{2}{|c|}{$E(\%)$} & \multicolumn{2}{|c|}{$\mathrm{B}(\%)$} \\
\hline & & & & & Mean & SE & Mean & SE & Mean & SE & Mean & SE & Mean & SE & Mean & SE \\
\hline I & Control $(0 \mathrm{mg} / \mathrm{kg})$ & $M$ & 7.20 & 0.04 & 9.37 & 0.65 & 21.50 & 0.64 & 73.10 & 0.58 & 3.20 & 0.19 & 1.70 & 0.11 & 0.50 & 0.05 \\
\hline II & $0.062 \mathrm{mg} / \mathrm{kg}$ & $\mathrm{M}$ & 7.48 & 0.14 & 8.28 & 0.13 & 21.40 & 0.12 & 72.90 & 0.26 & 3.60 & 0.13 & 1.50 & 0.17 & 0.60 & 0.04 \\
\hline III & $0.125 \mathrm{mg} / \mathrm{kg}$ & M & 7.35 & 0.18 & $7.21^{*}$ & 0.25 & $19.33^{*}$ & 0.32 & 74.44 & 0.31 & 3.66 & 0.29 & 2.08 & 0.22 & 0.48 & 0.05 \\
\hline IV & $0.250 \mathrm{mg} / \mathrm{kg}$ & $M$ & $6.40^{* *}$ & 0.14 & $3.30^{* *}$ & 0.08 & $16.29^{\star *}$ & 0.58 & $77.07^{\star *}$ & 0.49 & 3.77 & 0.20 & 2.20 & 0.27 & 0.67 & 0.07 \\
\hline 1 & Control $(0 \mathrm{mg} / \mathrm{kg})$ & $\mathrm{F}$ & 7.12 & 0.06 & 7.48 & 1.05 & 21.63 & 1.71 & 72.72 & 0.16 & 3.55 & 0.16 & 1.60 & 0.15 & 0.50 & 0.04 \\
\hline
\end{tabular}

N: Neutrophil, L: Lymphocyte, M: Monocyte, E: Eosinophil, B: Basophil, *: Significant $(p<0.05)$; **: Highly significant $(p<0.01)$

of Veterinary College, Anand Agriculture University has accorded permission for conducting this biological trial.

Medication: Study was conducted on colony-bred 7-8 weeks old, adult male and female albino wistar rats, procured from Division of Pharmacology and Toxicology, Cadila Pharmaceuticals Limited, Dholaka, Gujarat, India. The rats were housed in laboratory animal house in polypropylene cages and weighed weekly during the study. Feed and distilled water were provided ad libitum. All the 48 rats were randomly divided into 4 different groups. Each group consisted of 6 male and 6 female rats. The groups were numbered as group I to IV. The group I served as control and received only vehicle (Distilled water), while group II, III and IV received methotrexate at doses of $0.062 \mathrm{mg} / \mathrm{kg}$ (low dose), 0.125 $\mathrm{mg} / \mathrm{kg}$ (mid dose) and $0.250 \mathrm{mg} / \mathrm{kg}$ (high dose) respectively by oral gavage for 28 days of dosing period. At the end of 28 days i.e. termination of experiment, all the rats were subjected to terminal sacrifice by high dose of anesthesia with Di-ethyl ether, after blood collection from retro-orbital plexus with the help of capillary tube as described by Sorg and Buckner [7].

Hematology: Hematological parameters were analyzed by automatic whole blood analyzer like TLC, DLC, TEC, Hb, PCV, MCV, MCH and MCHC.

Serum-biochemical analysis: Biochemical estimations were carried out by using diagnostic kits (Merck Limited, India Ecoline Range) regarding AST, ALT, AKP, Serum creatinine, BUN, Total protein, Albumin and Globulin (Calculated).

Histopathology: Tissue samples from liver, kidney, lung, spleen, heart, intestine and testes were collected and preserved in $10 \%$ neutral buffer formalin for further histopathological examination.

\section{Results}

Male and female animals of group I (control) and II did not reveal any symptoms attributable to the 28 days administration of methotrexate. Two male and one female were found to be diarrhoeic in last week of experimental period in group III animals. Signs like dullness and lethargy were noticed in seven rats (four male and three female) of group IV animals. Two animals revealed diarrhoea in third week of experiment in high dose group whereas all other animals were found to be diarrhoeic in last week of experimental period in group IV animals.
Increase in live body weight was found in the male and female rats of group I (control) from 0 to $28^{\text {th }}$ day of exposure. While methotrexate treated rats of group III and IV showed weight loss on seventh day onward, there was no significant $(\mathrm{p}<0.05)$ change observed in body weight of male and female rats belonging to group II as compared to the respective control group I rats. The most significant $(\mathrm{p}<0.01)$ dose dependent reduction in body weight in male rats at $28^{\text {th }}$ day of experiment was observed in group IV (255.05 g) followed by significant reduction in group III (335.33 g) as compared with control group I (368.53 g) rats. In the treatment groups of female rats also, the dose dependent reduction in body weight gain was observed in last week of experiment as compared to the control group except group II.

Dose dependent highly significant $(p<0.01)$ reduction in mean values of feed consumption was observed throughout the experiment in group III and IV as compared to control group rats.

Hematological study revealed that there was a highly significant reduction $(\mathrm{p}<0.01)$ in $\mathrm{RBC}, \mathrm{Hb}$, PCV, WBC, neutrophil, lymphocytes of group IV males and in $\mathrm{RBC}$ and $\mathrm{WBC}$ of group IV females. A significant increase $(p<0.05)$ was also observed in MCV, $\mathrm{MCH}$ of group IV males, WBC and neutrophils of group III males, $\mathrm{Hb}, \mathrm{PCV}, \mathrm{MCV}, \mathrm{MCH}$, neutrophils, lymphocytes of group IV females and WBC of group III females. The rest of the rats from group II and III did not reveal any significant change in the above mentioned parameters as compared to control rats. No rat was observed with any significant change in MCHC, monocytes, basophils and eosinophils as compared to control rats (Table-1a, 1b).

Serum biochemical parameters: There is a highly significant increase $(p<0.01)$ observed in AST, ALT, AKP, Creatinine, BUN, total protein and albumin of group IV male and female rats and significant change $(p<0.05)$ observed in male and female rats of group III (Table-2a and $2 \mathrm{~b}$ ). There was no significant change observed in globulin value in any of the groups.

\section{Histopathology}

Liver: Grossly, no appreciable changes were observed in group I (control) and group II rats while liver was larger, pale and fatty in treatment group III and IV with mild to moderate congestion on its surface.

Histopathological changes in liver of rats treated 
Table-1b: Mean hematological values in different experimental groups.

\begin{tabular}{|c|c|c|c|c|c|c|c|c|c|c|c|c|}
\hline \multirow[t]{2}{*}{ Group } & \multirow[t]{2}{*}{ Dose } & \multirow[t]{2}{*}{ Sex } & \multicolumn{2}{|c|}{$\mathrm{Hb}(\mathrm{g} / \mathrm{dL})$} & \multicolumn{2}{|c|}{ PCV (\%) } & \multicolumn{2}{|c|}{ MCV (fL) } & \multicolumn{2}{|c|}{$\mathrm{MCH}(\mathrm{pg})$} & \multicolumn{2}{|c|}{$\mathrm{MCHC}(\mathrm{g} / \mathrm{dL})$} \\
\hline & & & Mean & SE & Mean & SE & Mean & SE & Mean & SE & Mean & SE \\
\hline I & Control(0 mg/kg) & M & 14.30 & 0.03 & 42.90 & 0.23 & 59.58 & 0.70 & 19.86 & 0.36 & 33.34 & 0.18 \\
\hline II & $0.062 \mathrm{mg} / \mathrm{kg}$ & M & 14.56 & 0.23 & 43.68 & 0.69 & 58.42 & 0.23 & 19.48 & 0.08 & 33.33 & 0.01 \\
\hline III & $0.125 \mathrm{mg} / \mathrm{kg}$ & M & 14.45 & 0.19 & 43.35 & 0.56 & 59.06 & 0.65 & 19.60 & 0.23 & 33.32 & 0.01 \\
\hline IV & $0.250 \mathrm{mg} / \mathrm{kg}$ & $\mathrm{M}$ & $13.35^{* *}$ & 0.16 & $40.02^{* *}$ & 0.48 & $62.57^{*}$ & 0.67 & $20.86^{*}$ & 0.22 & 33.34 & 0.01 \\
\hline I & Control (0 mg/kg) & $\mathrm{F}$ & 14.25 & 0.24 & 42.74 & 0.72 & 59.95 & 0.57 & 19.98 & 0.21 & 33.34 & 0.01 \\
\hline II & $0.062 \mathrm{mg} / \mathrm{kg}$ & $\mathrm{F}$ & 14.37 & 0.23 & 43.11 & 0.70 & 59.45 & 0.44 & 19.83 & 0.15 & 33.33 & 0.01 \\
\hline III & $0.125 \mathrm{mg} / \mathrm{kg}$ & $\mathrm{F}$ & 14.12 & 0.17 & 42.34 & 0.52 & 59.64 & 0.18 & 19.88 & 0.06 & 33.34 & 0.01 \\
\hline IV & $0.250 \mathrm{mg} / \mathrm{kg}$ & $\mathrm{F}$ & $13.48^{*}$ & 0.12 & $40.45^{*}$ & 0.37 & $62.23^{*}$ & 0.44 & $20.74^{*}$ & 0.15 & 33.33 & 0.01 \\
\hline
\end{tabular}

$*$ : Significant $(p<0.05)$; **: Highly significant $(p<0.01)$

Table-2a: Mean values of serum biochemical parameters in males of different experimental groups

\begin{tabular}{|c|c|c|c|c|c|c|c|c|}
\hline \multirow[t]{2}{*}{ Biochemical parameter } & \multicolumn{2}{|c|}{ Group I Control (0 mg/kg) } & \multicolumn{2}{|c|}{ Group II $(0.062 \mathrm{mg} / \mathrm{kg})$} & \multicolumn{2}{|c|}{ Group III (0.125 mg/kg) } & \multicolumn{2}{|c|}{ Group IV $(0.250 \mathrm{mg} / \mathrm{kg})$} \\
\hline & Mean & SE & Mean & SE & Mean & SE & Mean & SE \\
\hline AST (IU/L) & 141.20 & 0.81 & 142.50 & 1.46 & $150.90^{*}$ & 2.63 & $161.60^{* *}$ & 1.24 \\
\hline ALT (IU/L) & 45.20 & 0.43 & 47.30 & 1.73 & $48.00^{*}$ & 0.87 & $58.30^{\star *}$ & 0.92 \\
\hline AKP (IU/L) & 162.20 & 1.22 & 160.20 & 1.19 & $167.50^{*}$ & 1.63 & $198.00^{* *}$ & 1.07 \\
\hline Creatinine $(\mathrm{mg} / \mathrm{dL})$ & 0.48 & 0.04 & 0.56 & 0.02 & $0.61^{*}$ & 0.02 & $0.84^{* *}$ & 0.01 \\
\hline BUN (mg/dL) & 14.20 & 0.88 & 15.40 & 0.33 & $17.00^{*}$ & 0.23 & $19.90^{* *}$ & 0.34 \\
\hline Total protein $(\mathrm{g} / \mathrm{dL})$ & 7.12 & 0.10 & 6.90 & 0.11 & $6.48^{*}$ & 0.20 & $5.98^{\star \star}$ & 0.07 \\
\hline Albumin ( $/ \mathrm{dL})$ & 4.15 & 0.05 & 4.04 & 0.04 & $3.83^{*}$ & 0.09 & $3.22^{\star \star}$ & 0.05 \\
\hline Globulin (g/dL) & 2.97 & 0.13 & 2.85 & 0.10 & 2.64 & 0.16 & 2.76 & 0.09 \\
\hline
\end{tabular}

*: Significant $(\mathrm{p}<0.05)$; **: Highly significant $(\mathrm{p}<0.01)$

Table-2b: Mean values of serum biochemical parameters in males of different experimental groups

\begin{tabular}{|c|c|c|c|c|c|c|c|c|}
\hline \multirow[t]{2}{*}{ Biochemical parameter } & \multicolumn{2}{|c|}{ Group I Control (0 mg/kg) } & \multicolumn{2}{|c|}{ Group II (0.062 mg/kg) } & \multicolumn{2}{|c|}{ Group III (0.125 mg/kg) } & \multicolumn{2}{|c|}{ Group IV (0.250 mg/kg) } \\
\hline & Mean & SE & Mean & SE & Mean & SE & Mean & SE \\
\hline AST (IU/L) & 142.30 & 1.41 & 143.80 & 1.19 & $150.90^{*}$ & 2.53 & $160.40^{* *}$ & 0.69 \\
\hline ALT (IU/L) & 42.10 & 0.40 & 43.20 & 0.57 & $44.50^{*}$ & 0.69 & $57.70^{* *}$ & 0.86 \\
\hline AKP (IU/L) & 156.20 & 1.58 & 155.10 & 1.15 & $162.80^{*}$ & 1.92 & $195.10^{* *}$ & 2.33 \\
\hline Creatinine $(\mathrm{mg} / \mathrm{dL})$ & 0.49 & 0.04 & 0.58 & 0.02 & $0.64^{*}$ & 0.02 & $0.82^{* *}$ & 0.01 \\
\hline $\mathrm{BUN}(\mathrm{mg} / \mathrm{dL})$ & 14.50 & 0.84 & 15.80 & 0.19 & $16.90^{*}$ & 0.21 & $19.90^{* *}$ & 0.24 \\
\hline Total protein $(\mathrm{g} / \mathrm{dL})$ & 7.22 & 0.09 & 6.98 & 0.07 & $6.56^{*}$ & 0.19 & $6.14^{* *}$ & 0.10 \\
\hline Albumin ( $/ \mathrm{dL})$ & 4.18 & 0.07 & 4.00 & 0.04 & $3.83^{*}$ & 0.12 & $3.32^{* *}$ & 0.05 \\
\hline Globulin (g/dL) & 3.04 & 0.12 & 2.97 & 0.04 & 2.73 & 0.20 & 2.82 & 0.14 \\
\hline
\end{tabular}

*: Significant $(\mathrm{p}<0.05)$; **: Highly significant $(\mathrm{p}<0.01)$

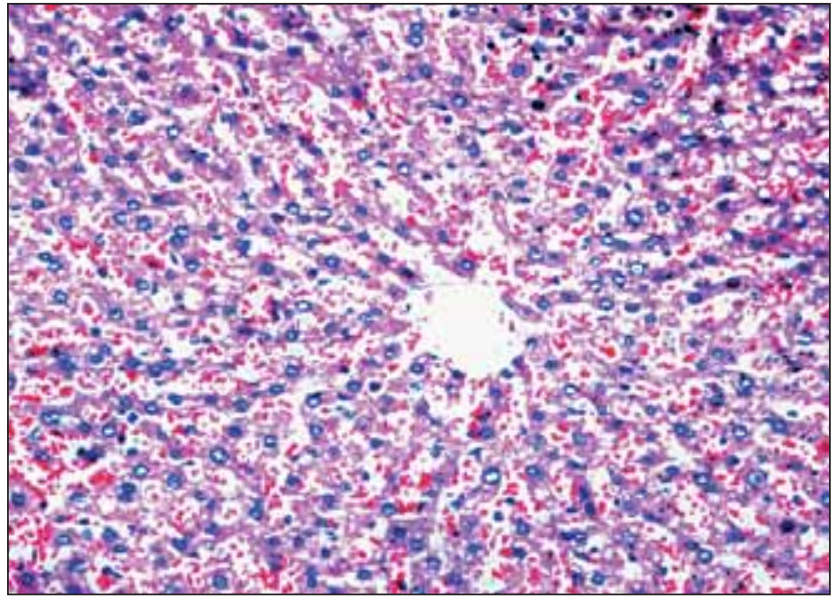

Figure-1: Section of liver from group IV showing sinusoidal haemorrhages with distortion of hepatic cords. H\&E, X300.

with different dose levels revealed dose dependent variation in degeneration as well as vascular changes. Mild to moderate granularity of hepatocytes and fatty changes were observed in the animals of group III. Animals of group IV showed vacuolar degeneration and the central vein was dilated and congested. At some places, sinusoids were found dilated and pronounced scattered hemorrhages with distortion of hepatic cords

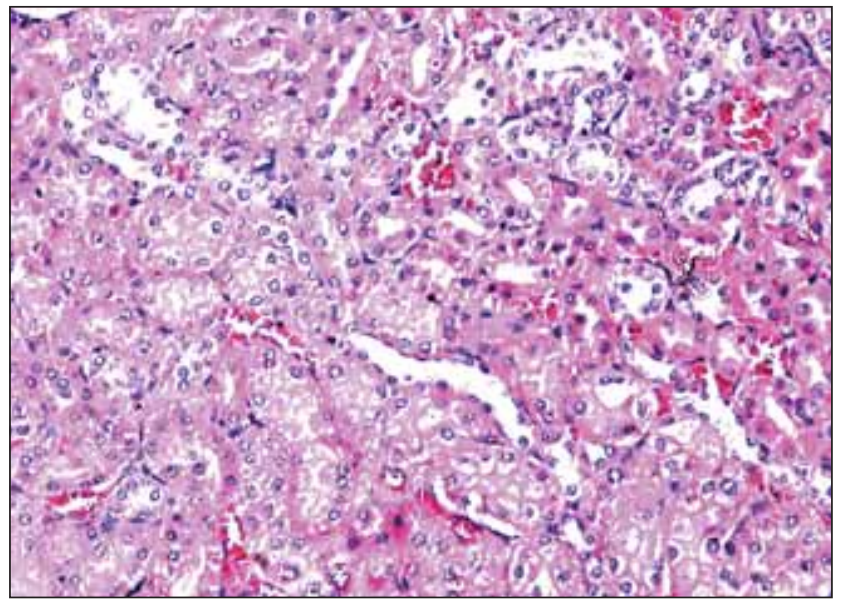

Figure-2: Section of Kidney from group III showing congestion and vacuolar degeneration of tubular epithelium. $H \& E, X 300$.

(Figure-1) in group IV rats.

Kidney: Sections from most of the animals in group III showed severe congestion and vacuolar degeneration of tubular epithelium (Figure-2). Sections from all the animals of group IV showed mild to moderate tubular necrosis (Figure-3) with vacuolar degeneration in the cytoplasm of tubular cells. Lesions in group III and IV rats were not only restricted to tubules but were also observed 


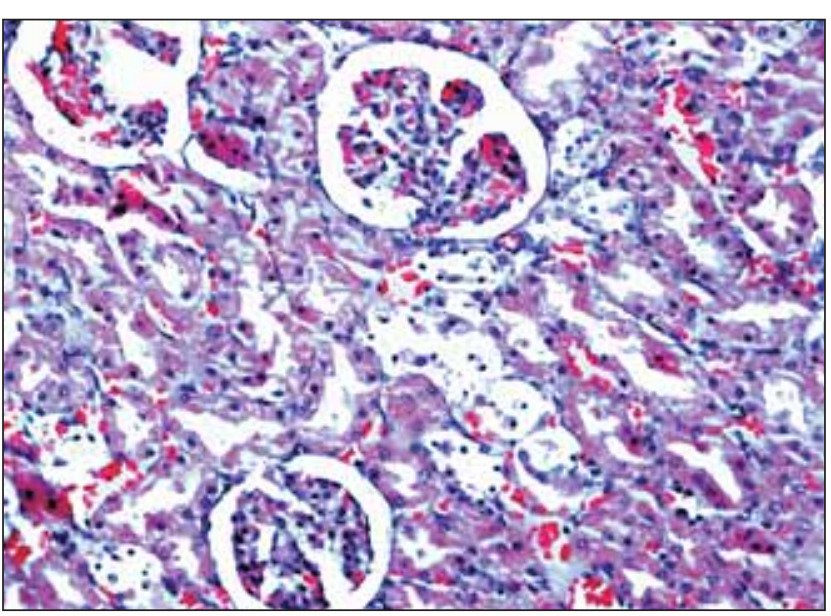

Figure-3: Section of kidney from group IV showing mild tubular necrosis. H\&E, X300.

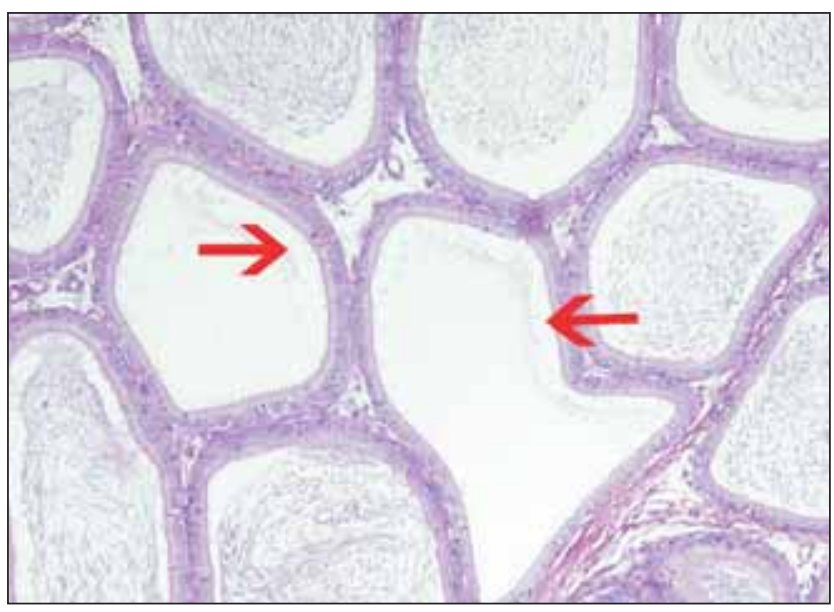

Figure-5: Section of epididymis from group IV showing reduced sperm concentration (arrow). H\&E, X150.

in glomeruli, there was increased space between the parietal and visceral layers of Bowman's capsule and focal infiltration of mononuclear cells. In group III and group IV rats, in addition to degenerative changes, moderate to severe vascular changes characterized by hemorrhages in between the tubules were observed.

Testes: Grossly, testes of group IV rats were swollen and showed bulging at cut surface, unlike in group I, II and III. The testes of rats of group IV showed mild atrophy of seminiferous tubules and mild to moderate sloughing of germ cells (Figure-4). No histopathological lesions were observed in testes of rats of group I, II and III.

Epididymis: No histopathological lesions were observed in epididymis of rats of control group I, II and III. The histopathological lesions observed in epididymis of rats of group IV showed reduced sperm concentration in epididymal tubules (Figure-5).

Lung: Gross lesions in lung were mainly characterized by mild to moderate congestion and emphysema in rats belonging to group III and IV as compared to group II and control. Microscopic changes in lungs of group III animals revealed congestion and hemorrhages in the alveoli. Besides these, pulmonary emphysema characterized by distension and dilatation of alveoli was also

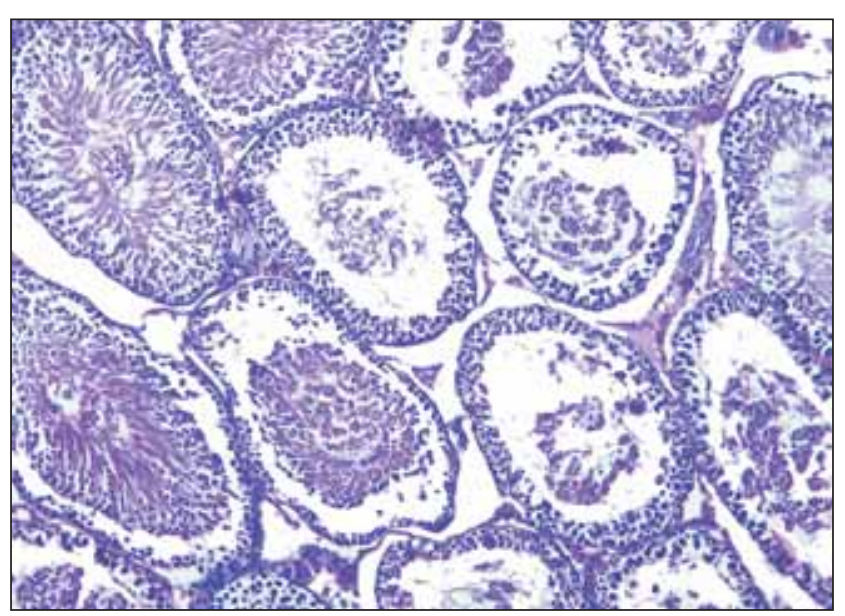

Figure-4: Section of Testis from group IV showing sloughing of germ cells. $\mathrm{H} \& \mathrm{E}, \mathrm{X} 150$

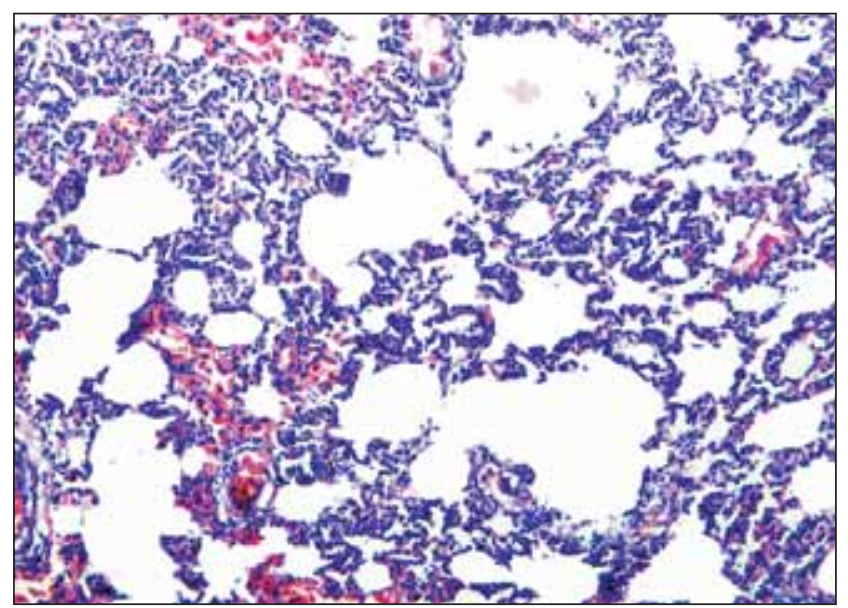

Figure-6: Section of lung from group IV showing thickening and infiltration of mononuclear cells in the interstitial space. $H \& E, X 150$.

evident at some places. Microscopically emphysema, thickening and mononuclear cell infiltration in interstitial space (Figure-6) and focal haemorrhages were noticed in the animals of group IV.

Spleen: No gross pathological lesions were observed in any of the treatment group except mild congestion and enlargement of spleen with varying degree of deposition of haemosiderin pigments (Figure-7) in few animals of group IV as compared to the control.

Intestine: No gross lesions were seen in group I (control) and group II animals unlike group IV which showed mild congestion in mucosa. The microscopic lesions were characterized by desquamation and denudation of surface epithelium of the villi leading to erosions and necrosis. The necrotic area on the villi showed neutrophilic infiltration (Figure-8) in group IV rats. Section of intestine from group I (control), II and III animals did not reveal any histopathological changes.

\section{Discussion}

It was found in present study that high dose of methotrexate causes gastrointestinal toxicity in rats which resulted in diarrhoea and nasal bleeding. Similar results were also reported by Ermens et al. [8] and Boukhettala et al. [9]. In the present study, clinical 


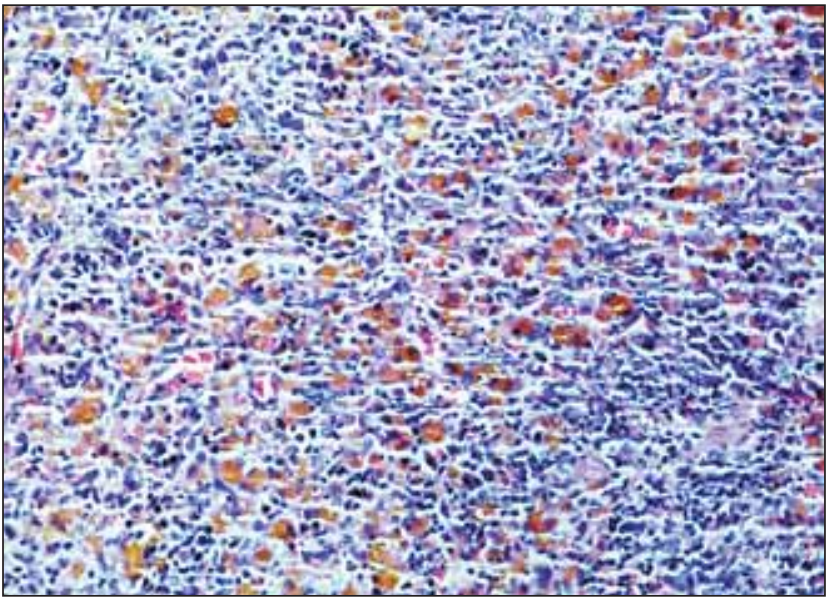

Figure-7: Section of spleen of group IV showing deposition of haemosiderin pigment. $H \& E, X 300$.

signs like dullness and lethargy developed as there was decrease in feed consumption and body weight due to methotrexate toxicity. Group III and IV animals showed diarrhoea, the possible reason for these could be corrosive and irritating effects of methotrexate on gastrointestinal mucosa. No mortality was found in any dose groups. Weight loss in methotrexate treated rats might be a reflection of direct toxicity, reduced feed and water intake and stressogenic activity, which are in agreement with earlier studies carried out by Perianayagasamy et al. [10] and Karri and Vanithakumari [11] in their studies.

Significant decrease in RBCs counts were observed in the treatment group IV and WBC counts in group III and IV. The change in RBCs count can be attributed to ulcers in the digestive tract resulting in gradual blood loss which supports the findings of the Ohbayashi et al. [12]. Decrease in PCV values in treatment group IV rats could be due to cytotoxic effect of methotrexate on haemopoietic system as evident from state of anemia. Similar observations of decrease in WBC counts were also made by Rofe et al. [13] and Bussanich et al. [14]. Decreased feed consumption leading to hypoproteinemia could be another possible cause for lower haemoglobin seen in the present study. The findings of the current study are in accordance with Ohbayashi et al. [12] who treated mice with methotrexate at the dose of 3,10 and $15 \mathrm{mg} / \mathrm{kg}$ for 28 consecutive days and observed decreased level of $\mathrm{Hb}$ and PCV in dose dependent manner. Rofe et al. [13] reported the hematological changes in female dark agouti rats treated with methotrexate at the dose rate of $0.5 \mathrm{mg} / \mathrm{kg}$ two intramuscular injections, 24 hours apart and observed the slight increase (but not significant) in levels of $\mathrm{Hb}$ and PCV.

In present study, decrease in the neutrophil count was observed with increase in lymphocyte count in high dose group. Similarly, Robert et al. [15] reported the systemic effect of methotrexate at the dose rate of $1.7 \mathrm{mg}$ or $5 \mathrm{mg}$ intraperitoneally every 48 hours in guinea pigs and observed that the differential leucocyte

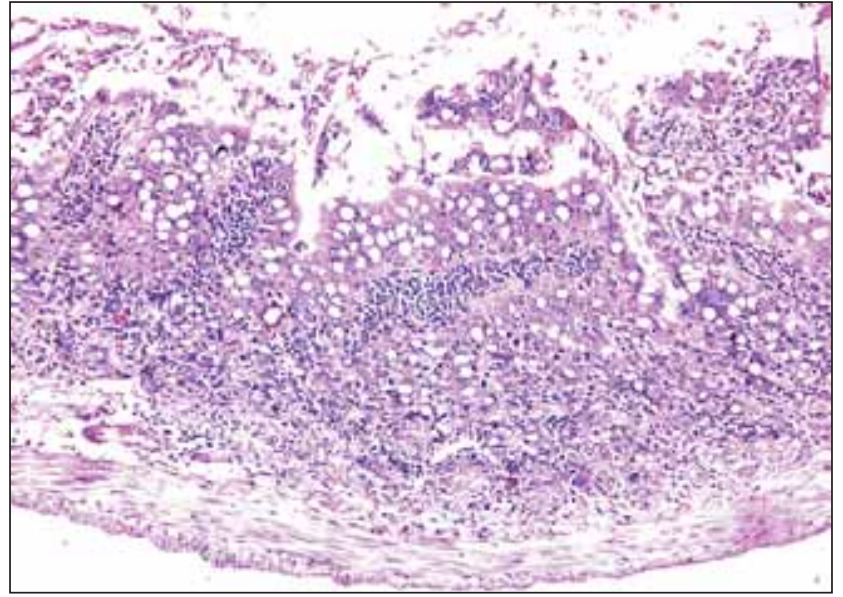

Figure-8: Section of intestine from group IV showing necrosis at the tip of villi with neutrophilic infiltration. H\&E, X150.

counts changed from 66\% lymphocytes before drug administration to $90 \%$ after 2 weeks and polymorphonuclear counts dropped from 34 to $10 \%$ during this period.

In the present study, group III and IV had significant increase in the value of AST which are in accordance with the findings of Vaghasiya et al. [16] who evaluated the effect of polyherbal formulation on methotrexate induced hepatotoxicity in rats at the dose rate of $1 \mathrm{mg} / \mathrm{kg} / \mathrm{p}$.o./week for 3 weeks and exhibited significant increase in levels of AST. Increased level of AST indicated damage caused by methotrexate toxicity to the visceral organs.

Significant increase in the value of ALT in group III and IV are in accordance with Uraz et al. [17] who reported increased levels of ALT by single dose of methotrexate. Vaghasiya et al. [16] also reported increase in level of ALT in their study. ALT enzyme is liver specific and present in hepatocyte cytoplasm [18]. Increased ALT level in present study indicates liver damage in the rats exposed to $0.125 \mathrm{mg} / \mathrm{kg} \mathrm{b}$. wt/day and $0.250 \mathrm{mg} / \mathrm{kg} \mathrm{b}$. wt/day administration of methotrexate.

Perianayagasamy et al. [10] evaluated the therapeutical effect of melatonin and glutamine against rats bone marrow toxicity induced by methotrexate in rat. Methotrexate was given in rat at the dose rate of 400 $\mu \mathrm{g} / 150 \mathrm{~g}$ of body weight for 7 days and showed increase in alkaline phosphatase level. Similar observations were also made by Vaghasiya et al. [16] and Uraz et al. [17]. Increase in the level of AKP in group III and group IV indicated significant damage to the body tissues by methotrexate resulting in liberation of AKP in serum.

In present study, there was highly significant increase in the levels of creatinine and BUN in methotrexate treated group IV, significant increase in group III and a slight but not significant increase in group II. These results indicate that the reduction in renal filtration rate can be due to toxic effect of methotrexate on kidney. This is supported by histopathological observation on kidney tissue revealing tubular degeneration and necrosis in treatment groups.

Similar findings of decrease in total protein and 
albumin and no significant change in globulin were also reported by Vaghasiya et al. [16]. Decrease in level of total protein is also in accordance with the findings of Perianayagasamy et al. [10]. Reduction in serum total protein and serum albumin induced by methotrexate treatment could be due to several factors like damage to liver, increased intestinal protein loss, protein-losing nephropathy and dietary protein deficiency as there was decrease in feed intake.

Al-motabagani [19] reported the histological and histochemical studies on the effects of methotrexate on the liver of adult male albino rat and showed heavy cell infiltration around the portal tract and vacuolation of the cytoplasm of hepatocyte. Vaghasiya et al. [16] also showed vacuolation, degeneration of hepatocyte and mild inflammation. Asci et al. [20] revealed similar histopathological changes such as focal inflammatory cell infiltrations, vascular congestion, sinusoidal dilatation and granular degeneration of hepatocytes. The results of present study indicated that the methotrexate has a direct participation in liver structures alterations and causes the cytotoxicity of hepatocytes with vacuolation of hepatic cytoplasm. These types of changes in the tissues might be due to hypoxia as a result of anaemia which causes mild and easily reversible changes in parenchymatous organs.

The kidney lesions in group III and IV were in accordance with the findings of Chelab and Mazeed [21] who studied histopathological changes in kidneys due to prolonged treatment (6 months) with anticancer chemotherapeutic agent namely methotrexate and showed the damage and severe toxicity in renal convoluted tubules and glomeruli in kidneys. Histopathological findings in kidneys are in agreement with the biochemical findings like increased levels of serum creatinine, due to decrease in glomerular filtration rate of methotrexate and its metabolites from kidneys, which may lead to kidney lesions because of irritation caused by deposition of methotrexate crystal in nephrons causing the nephrotoxicity [22].

Histopathological lesions of testes were in accordance with Arash et al. [23] who studied the effect of growth hormone on recovery from testicular damage induced by methotrexate in rats at the dose rate of 1 $\mathrm{mg} / \mathrm{kg} /$ week intraperitoneally for 4 weeks and confirmed the destructive effects of methotrexate on testicular germinal cells with decrease in sperm count. Khulood et al. [24] reported significant $(\mathrm{p}<0.05)$ decrease in diameters of seminiferous tubules, primary spermatocytes and spermatids and increased interstitial spaces in comparison to control while studying the effects of aqueous extract of Salvia on some parameters of sperms and histopathological changes in testes of mice treated with methotrexate. Similar observations were also made by Safavi et al. [25] by administration of $1 \mathrm{mg} / \mathrm{kg}$ methotrexate intraperitonially for 28 consecutive days in rats.

Histopathological lesions of lungs suggest that methotrexate could induce alveolar epithelial cell injury and resulted in the loss of integrity of the alveolar capillary barrier basement membranes followed by the recruitment and proliferation of myofibroblasts which may cause the thickening of alveolar septa and mononuclear cell infiltration in interstitial space. Similar observations were also reported by Ohbayashi et al. [12] in their study in which they treated mice with methotrexate at a dose of $3 \mathrm{mg} / \mathrm{kg}$ once a day for 21,28 , and 35 consecutive days. After 35 days, alveolar septa were increased slightly along with hyperplasia of interstitial tissue as compared with control animals.

Histopathological results of intestine were similar to the findings of Boukhettala et al. [9] who reported marked decrease of villous height at day four, inflammation and intestinal epithelial necrosis in the male Sprague Dawley rats which received subcutaneous 2.5 $\mathrm{mg} / \mathrm{kg}$ of methotrexate for 3 days.

\section{Conclusion}

Methotrexate administration at recommended dosage $(0.062 \mathrm{mg} / \mathrm{kg} /$ body weight $)$ revealed no appreciable changes while high dosage $(0.250 \mathrm{mg} / \mathrm{kg} /$ body weight) showed decrease in body weight and feed consumption, $\mathrm{Hb}, \mathrm{PCV}$, TEC, TLC, neutrophil counts, serum total protein and albumin values and significant increase in $\mathrm{MCV}, \mathrm{MCH}$ and lymphocyte count. Significant increase in the AST, ALT, AKP, creatinine and BUN were suggestive of histopathological lesions observed in liver and kidney. Finally it can be concluded from this study that sub-acute exposure to methotrexate produced no appreciable changes at recommended $0.062 \mathrm{mg} / \mathrm{kg}$ body weight dose level. The findings observed at 0.125 and $0.250 \mathrm{mg} / \mathrm{kg}$ body weight methotrexate dose level are of public health significance and regulatory importance.

\section{Authors' contributions}

This study is the major component of the work towards the M.V.Sc thesis of NNP, under the guidance of the second author DJG. NNP conducted the experimental trials and organized the manuscript and DJG thoroughly revised the same. BPJ and CJD were the members of the advisory committee for the research work. SP, PDG and JHK were responsible for the housing and management of rats and helped in post mortem examination, blood collection, serum biochemical investigation, data analysis and interpretation. All authors read and approved the final manuscript.

\section{Acknowledgements}

The authors express profound gratitude to Anand Agricultural University (AAU), Anand, Gujarat and Dean, College of Veterinary Science and Animal Husbandry, AAU for providing the infrastructure facilities as well as financial help to carry out the research work.

\section{Competing interests}

The authors declare that they have no competing interests. 


\section{References}

1. Kremer, J. M. and Lee, J. K. (1988) A long term prospective study of the use of methotrexate in rheumatoid arthritis. Arthritis Rheum., 31:577-584.

2. Harris, E. D. (1990) Rheumatoid arthritis. Pathophysiology and implication for therapy. N Engl.J. Med. 322: 1277-1289.

3. Clavel, M., Vermorken, J. B. and Cognetti, F. (1994) Randomized comparison of cisplatin, methotrexate, bleomycin and vincristine versus cisplatin and 5 fluorouracil versus cisplatin in recurrent or metastatic squamous cell carcinoma of the head and neck. A phase III study of the EORTC head and neck cancer co-operative group. Ann. Oncol. 5: 521-526.

4. Sterling, G. (1997) Methotrexate hepatotoxicity. Rheum Dis Clin NAm. 23(4): 883-915.

5. Hall, P. D., Jenner, M. A. and Ahern, M. J. (1991) Hepatotoxicity in a rat model caused by orally administered methotrexate. Hepatology. 14(5): 906-10.

6. Cash, J. M. and Klippel, J. H. (1994) Second line drug therapy for rheumatoid arthritis. N Engl J Med. 330: 13681375.

7. Sorg, D. A. and Buckner, B. (1964) A simple method of obtaining venous blood from small laboratory animals. Exp Biol Med. 115: 1131-2.

8. Ermens, A. A. M., Schoester, M., Spijkers, L. J. M., Lindemans, J. and Abels, J. (1989) Toxicity of methotrexate in rat pre - exposed to nitrous oxide. Cancer Res. 49: 63376341.

9. Boukhettala, N., Leblond, J., Claeyssens, S., Faure, M., Pessot, F. L., Feysot, C. B., Hassan, A., Mettraux, C., Vuichoud, J., Lavoinne, A., Breuille, D., De'chelotte, P. and Coeffier, M. (2009) Intestinal mucositis and alters gut protein metabolism independently of reduced food intake. $\mathrm{Am} \mathrm{J}$ Physiol-Endoc M. 296: 182-190.

10. Perianayagasamy, A. M., Gomez, P. P. and Dhasarathan, P. (2010) Therapeutical effect of melatonin and glutamine against rats bone marrow toxicity induced by methotrexate. J. Bio sci. Res .1(3): 202-207.

11. Karri, S. and Vanithakumari, G. (2011) Effect of methotrexate and leucovorin on female reproductive tract of albino rats. Cell Biochem Funct. 29: 1-21.

12. Ohbayashi, M., Suzuki, M., Yashiro, Y., Fukuwaka, S., Yasuda, M., Kohyama, N., Kobayashi, Y. and Yamamoto, T. (2010) Induction of pulmonary fibrosis by methotrexate treatment in mice lung in vivo and in vitro. $J$ Toxicol Sci. 35(5): 653-661.

13. Rofe, A. M., Bourgeois, C. S., Washington, J. M., Philcox, J. C. and Coyle, P. (1994) Metabolic consequences of methotrexate therapy in tumour bearing rats. Immunol Cell Biol. 72: 43-48.

14. Bussanich, M. N., Rootman, J., Kumi, C. and Gudauskas, G. (1985) Ocular absorption and toxicity of methotrexate in the dog. Can. Vet J. 26:263-266.

15. Robert, M. F., Buckler, C. E. and Baron, S. (1961) The effect of amino methyl pteroylglutamic acid on the development of skin hypersensitivity and on antibody formation in guinea pigs. United States Department of Health, Education and Welfare, Public Health Service, National Institute of Health, Division of Biologics Standards, laboratory of viral immunology, Bethesda. 173-183.

16. Vaghasiya, J., Bhalodia, Y. and Rathod, S. (2009) Drug induced hepatotoxicity: effect of polyherbal formulation. Phcog Mag 5:232-237.

17. Uraz, S., Tahan, V., Aygun, C., Eren, F., Unluguzel, G., Yuksel, M., Senturk, O., Avsar, E., Haklar, G., Celikel, C., Hulagu, S. and Tozun, N. (2008) Role of ursodeoxycholic acid in prevention of methotrexate induced liver toxicity. Dig Dis Sci. 53: 1071-1077.

18. Coles, E. H. (1986) Veterinary clinical pathology. $4^{\text {th }}$ edition (ed. E. H. Coles) W. B. Saunders company, Philadelphia. p10-42.

19. Al-motabagani, M. A. (2006) Histological and histochemical studies on the effects of methotrexate on the liver of adult male albino rat. Int. J. Morphol. 24(3): 417-422.

20. Asci, H., Ozer, M. K., Calapoglu, M., Savran, M., Oncu, M., Yesilot, S., Candan, I. A., Kulac, E. and Cicek, E. (2011) Effects of misoprostol on methotrexate induced hepatic and renal damages. J. Biol. Life. Sci. 2(1):32-37.

21. Chelab, K. G. and Majeed, S. K. (2009) Methotrexate induced histopathological changes in the kidneys of mice. Iraqi J. Vet. Sci. 23:219-222.

22. Hanley M. J. (1980) Isolated nephron segments in a rabbit model of ischemic acute renal failure. Am. J. Physiol. 239: 17-13.

23. Arash, K., Novin, M. G., Khaki, A. A., Nouri, M. and Ozanci, C. C. (2007) Effect of growth hormone on recovery from testicular damage induced by methotrexate in rat. Reprod Toxicol. 01/2008; 26(1):65-65.

24. Khulood, W., Ismaeel A. H. and Abdulatif, A. W. (2010) Effects of aqueous extract of salvia on some parameters of sperms and histopathological changes in testes of mice treated with methotrexate. J. Biotechnol. Res. Center. 4(2): 3-10.

25. Safavi, S. E., Khayat, N. M. H., Khaki, A. and Serati N. H. (2010) Effect of growth hormone on histomorphometerical parameters of testis after methotrexate administration in rat. Vet. Res. 6(1): 23-29. 